\title{
Effects of Chronic Alcohol Consumption on Hippocampal Anatomy and Associated Behaviors in Three Inbred Strains of Mice
}

\author{
Yann S. Mineur ${ }^{1}$, Charlotte C.G. Marican ${ }^{2}$, Christiane Larue-Achagiotis ${ }^{3}$, Frans Sluyter ${ }^{4}$ and \\ Wim E. Crusio ${ }^{*}, 5$
}

\author{
${ }^{I}$ Yale University School of Medicine, 34 Park Street, 3rd Floor Research, New Haven, CT, 06519, USA \\ ${ }^{2}$ Laboratoire de Neurobiologie de l'Apprentissage, de la Mémoire et de la Communication (NAMC), UMR 8620, \\ Université Paris Sud Bâtiment 446, 91405 Orsay Cedex, France \\ ${ }^{3}$ UMR914 Nutrition Physiology and Ingestive Behavior, INRA, AgroParisTech, 16 rue Claude Bernard, F-75005 Paris, \\ France \\ ${ }^{4}$ SGDP Research Centre, Institute of Psychiatry, 111 Denmark Hill, London 5SE 8AF, UK \\ ${ }^{5}$ Centre de Neurosciences Intégratives et Cognitives, Université de Bordeaux I and CNRS, Bat. B2-Avenue des \\ Facultés, 33405 Talence, France.
}

\begin{abstract}
The goal of this study was to investigate the influence of 6 months of chronic alcohol consumption on hippocampal neuroanatomy, notably the sizes of the intra- and infrapyramidal mossy fiber (IIPMF) terminal fields, and several behaviors, such as radial-maze learning, intermale aggression and anxiety-like behavior, in three inbred strains of mice (NZB, CBA/H, C57BL/6). Based upon several reports highlighting the toxicity of chronic alcohol exposure on the hippocampus, we expected a general diminution of cognitive abilities, with reduced spatial learning skills, increased aggression and anxiety; and concomitantly, a reduction in the sizes of the IIPMF. Contrary to our hypothesis, we did not find an effect of chronic alcohol exposure, neither an effect per se or in interaction with the genotype. Possible explanations for this unexpected finding include ageing effects and species differences between rats and mice.
\end{abstract}

Keywords: Alcohol, inbred mouse strains, spatial learning, hippocampus, aggression.

\section{INTRODUCTION}

Ethanol has a wide-range of physiological and behavioral effects, but remains one of the least understood psychoactive drugs. The main reason is that alcohol does not touch upon a simple interaction between ligand and receptor, but acts as a multipotential pharmacoactive substance. As evidenced by a current of publications, pinpointing a site of action or single mechanism underlying alcohol effects is difficult because the drug affects virtually all neurochemical and endocrine systems. Consequently, many studies have been carried out, each trying to understand specific pathways affected by alcohol. In this paper, we focus on the genetic susceptibility to the effects of chronic exposure to alcohol, a less frequently investigated part as most studies in this field have concentrated on the effects of chronic exposure to alcohol per se.

Long-term use of alcohol leads to multiple and durable changes in the central nervous system. Alcoholics exhibit brain lesions [1], such as reductions of the size of the forebrain and hippocampus [2], as well as neurodegenerative changes in the cholinergic basal forebrain [3]. In animal models, several groups have reported specific neuronal loss in the dentate gyrus, increased arborizations of the dendritic spines of the granule cells $[4,5]$, reduction of the number of

*Address correspondence to this author at the Centre de Neurosciences Intégratives et Cognitives, CNRS UMR 5228, Bat B2 - Avenue des Facultés, 33405 Talence, France; Tel: +33 54000 8900; Fax +33 54000 8743; E-mail:wimVंcrusio@yahoo.com spines of the CA3-pyramidal cells [6], and a reorganization of synaptic formations [7]. Chronic exposure to alcohol also induces long-term physiological changes, such as a decrease of specific neurotrophic factors $[8,9]$, and more generally, changes in patterns of neurotransmission [10]; for a review see [11]. Concomitantly, behavioral modifications are observed. Whereas the acute effect of alcohol is stimulatory and results in a behavioral "disinhibition" (e.g. exultation, euphoria, or desolation), long-term use provokes other patterns of behavior, subtle and variable according to age, sex, time of exposure, and models used [10, 12-14]. Not surprisingly given the plasticity of the brain, some of these toxic effects lessen or even disappear after withdrawal from alcohol $[7,15,16]$, although this may take several months [5]. However, most brain damage often remains irreversible [17]: for instance, alcoholics who had been consuming alcohol for a long time revealed damages and shrinkage in several brain regions $[1,2]$. In addition, the behavior of former alcoholics often does not recover completely [18].

Many reports have demonstrated that the effects of chronic exposure to alcohol on brain and behavior are variable from one person to another. Genetic factors, in interaction with environmental ones are likely to underlie these inter-individual differences (for review, see [19]. The aim of this study was to investigate the genetic susceptibility to chronic exposure of alcohol in a mouse model. To this end, mice from three inbred strains were exposed to an alcoholcontaining solution as their only source of fluid for 6 months. Necessary control groups (pair-feds, standard) were 
included. After an obligatory period of withdrawal in which all groups were housed under standard laboratory conditions, all animals were run through a behavioral test battery, including radial-maze learning, aggressive behavior (residentintruder and neutral cage paradigms), and anxiety-like behavior. Next, animals were sacrificed and the sizes of the hippocampal intra- and infrapyramidal mossy fiber (IIPMF) terminal fields were determined.

Bearing in mind that (i) long-term alcohol intake results in a loss of hippocampal pyramidal cells $[6,7,20]$, (ii) dendritic spines of these pyramidal cells induce growth of the IIPMF terminal fields [21], (iii) newly born cells in the dentate gyrus are highly demanding on neurotrophic factors [22, 23], and (iv) long-term alcohol exposure decreases the concentration of such factors [8], we hypothesized that chronic alcohol exposure would diminish the sizes of the IIPMF terminal fields. In consequence, we would expect animals exposed chronically to alcohol to perform poorly in the radial maze, because the extent of the IIPMF terminal fields is positively correlated with spatial navigation skills [24, 25]. We also anticipated an increase in aggression as this behavior is negatively correlated with the IIPMF sizes [26-29]. Finally, if aggressive behavior is indeed increased, we would expect more anxiety-like behavior in the Light/Dark box, given the correlation between these two behaviors (Guillot and Chapouthier, 1996).

The three strains used in this study, NZB/B1NJ (NZB), $\mathrm{CBA} / \mathrm{H}(\mathrm{CBA})$ and $\mathrm{C} 57 \mathrm{BL} / 6 \mathrm{~J}(\mathrm{~B} 6)$, have distinct genotypes and therefore each strain might be differentially protected against or be vulnerable to chronic alcohol exposure. In addition, these three strains differ in voluntary alcohol consumption (Fuller, 1978) as well as their sizes of the IIPMF terminal fields. Hence, instead of or in addition to a general effect of chronic alcohol exposure, we might expect a straindependent, differential response to chronic alcohol consumption, i.e., a gene-environment interaction.

\section{MATERIALS AND METHODS}

\section{Animals}

All experimental animals were born and raised in our former animal facility at the Université René Descartes in Paris, France, which was approved by the French Ministry of Agriculture. Animals were kept under the following conditions: temperature: $23 \pm 0.5^{\circ} \mathrm{C}$; light/dark schedule : 12:12, lights on at 8:00 AM; Food (IM UAR) and tap water ad libitum; dust-free sawdust bedding; weaning at approximately 4 weeks; housing in plastic cages (42 x 27 x 17) with littermates (not more than four per cage) until alcoholization commenced. Three inbred strains were used in this study: $\mathrm{NZB} / \mathrm{B} 1 \mathrm{NJ}, \mathrm{CBA} / \mathrm{H}$, and C57BL/6J. All strains had been maintained in our animal facility for several years. Only males were used. All experiments were performed in accordance with the applicable European Union and French regulations. WEC holds a valid French permit for animal experimentation (nr 3306013, Préfecture de la Gironde).

\section{Experimental Design}

At two months of age, animals from each strain were subdivided into three groups: (1) an alcohol group, which had its beverage replaced with a $15 \%$ ethanol solution $(\mathrm{v} / \mathrm{v})$; (2) a pair-fed group, which was provided with an isocaloric solution of dextrimaltose and served as a control for the alcohol group; (3) a non-treated control group which was supplied with regular tap water (standard laboratory procedure). Hence, nine groups (3 strains x 3 treatments) were created. This procedure was followed for six months. Liquid consumption and weight gain were similar across groups. After the period of alcohol consumption, mice were put back on a regular tap water regime for five consecutive weeks, as we wanted to avoid testing animals under influence or suffering from withdrawal effects. Animals were first tested in the LD box followed by the first aggression test (neutral-cage paradigm). Subsequently, their spatial learning was determined in the radial maze. Finally, animals were tested in the second aggression test (resident-intruder paradigm). All tests were separated in time by one week. At the beginning of the testing animals were 40 weeks of age.

\section{Light-Dark Box Test}

Anxiety was tested in the Light-Dark (LD) box, also known as the Black and White Box or two-compartment activity box. The LD box was first proposed by Crawley and Goodwin [30]) and further developed and validated by Costall and colleagues [31, 32] and Misslin and colleagues [33]. The version used in the present experiments was described previously by Guillot et al. [34]. Briefly, it consists of two darkened Plexiglas boxes of the same size $(23 \times 15 \times$ 15) $\mathrm{cm}$. The light box has a transparent cover and is illuminated by a $100 \mathrm{~W}$ desk lamp. Animals can cross from one box into the other through a small hole in the wall. Each mouse was placed in the illuminated box and observed for 5 minutes after the first entry in the dark box. A mouse whose four paws were in the next box was considered as having changed boxes. Behavioral variables were latency to the dark box, percentage of time spent in the light compartment, overall number of transitions between the light and dark box and defecation.

\section{Aggression Test}

Aggressive behavior was measured in two tests: the neutral-cage and the resident-intruder paradigm. In both tests a DBA/2J male (supplied by IFFA-CREDO, Lyon, France) of the same age was used as a standard opponent. This strain was used for its low propensity to attack as an intruder [35].

The neutral cage paradigm has been portrayed at length by Roubertoux et al. [36]. The test took place in a transparent Makrolon cage $(42 \times 26 \times 18 \mathrm{~cm})$ with a transparent lid. The floor was covered with a mix of sawdust from cages of different strains including the tested and DBA/2 animals. This procedure is known to accelerate the appearance of the first attack without affecting the proportion of males exhibiting at least one attack [37]. The experimental animal was placed in the test cage for a 2 minutes habituation period, after which a standard opponent was carefully put in the corner. Recording of the variables started when the experimental animal sniffed the opponent and lasted 6 minutes maximum. The experiment was stopped 2 minutes after the first attack of the experimental animal. The following behavioral variables were measured: latency to the first attack, number of attacks, number of tail rattlings, and number of attacking males.

The rationale of the second aggression test used in this study, the resident-intruder paradigm, has been explained 
elsewhere (see, among others Maxson 1992). Standard opponents were cautiously put in the corner of the home cage of the animal to be tested. The rest of the procedure and the behavioral variables measured were similar to those in the neutral cage test.

\section{Radial-Maze Test}

Spatial learning was tested in an 8-arm radial-maze [25, 38]. The central part of the radial maze measured $20 \mathrm{~cm}$ in diameter. Its arms (25 cm long, $6 \mathrm{~cm}$ high, $6 \mathrm{~cm}$ wide) were closed and made of transparent Plexiglas. At the end of each arm was a perforated partition behind which fresh food pellets were deposited. In this way, the presence or absence of a reward could not be smelled by the animals. All arms were reinforced by placing a small food pellet $(\sim 10 \mathrm{mg})$ behind a low barrier preventing the animal from seeing whether a specific arm was still baited or not. The maze was always oriented in space in the same way. Several extra-maze cues were provided close to the arms. A confinement procedure was used to disrupt chaining responses and kinesthetic strategies [38]. The radial maze was placed directly on the floor to avoid possible elevation-induced anxiety.

Animals were habituated for 1 day and subsequently trained for 5 days. The habituation consisted of a 15-minutes exploration trial with free access to all arms but without a food reward. Immediately afterwards they were deprived of food. During the training sessions, animals were kept at 80$90 \%$ of their original weight. On the first two days, trials were terminated after the animal had eaten all rewards. From day 3 up to 5, the time limit was set at 30 minutes. The situation of animals not eating all rewards occurred frequently on the first two days, but never on days 3 to 5. For this reason, data from days 1 and 2 were not included in the analysis. Two variables representing learning performances were sampled: the first variable is the number of errors. An error is noted if an animal enters an arm previously visited or does not eat the reward. The second variable is the number of new entries, the number of different arms visited during the first eight arm-visits. The maximum number of new entries is eight. A random choice of entries of the first eight arms leads to an expected mean of 5.3 [39].

\section{Hippocampal Morphometry}

Within a week following the radial maze test animals were sacrificed in order to measure the sizes of the hippocampal mossy fiber terminal fields. For a detailed description the reader is referred to $[38,40])$. Briefly, animals were deeply anesthetized and perfused intracardiacally with sodium sulfide and glutaraldehyde. Brains were removed and post-fixed 24 hours in $3 \%$ glutaraldehyde with $20 \%$ sucrose and subsequently cut horizontally in $40 \mu \mathrm{m}$ cryostat sections after which Timm's silver sulfide staining was applied [41].

Methods used for visualization and measurement of the hippocampal terminal fields were similar to those described previously $[38,42]$. Sampling started directly below the most ventral extension of the septal pole of the fascia dentata. Five defined horizontal sections per animal were pseudorandomly sampled, alternating between the left and right hippocampus, and taking every other section. The analysis of the mossy fiber (MF) terminal fields (CA4, suprapyramidal $\mathrm{MF}$, and IIPMF) was performed on a Macintosh computer using the public domain NIH Image program (developed at the U.S. National Institutes of Health and available on the Internet at http://rsb.info.nih.gov/nih-image/). Macros developed especially for such types of assessments allowed objective and standardized measurements. Sizes of the three mossy fiber terminal fields were expressed as percentages of the total mossy fiber size, limiting possible variations in cutting plane or tissue shrinkage. Results are expressed as percentages of total mossy fibers.

\section{Statistical Analyses}

The data of the LD box, aggression tests, and hippocampal morphometry were analyzed using a two-way ANOVA with genotype (or strain) (three levels: B6, CBA and NZB) and treatment (also three levels: alcohol, pair-fed, and control) as between-subject factors. Radial maze data were analyzed using a two-way repeated measures ANOVA, with training days 3 up to 5 as the within-subject factor and genotype and treatment as between-subject factors (both having the same levels as above). The numbers of new entries were tested against chance level (5.3) using a t-test. Least Square Means (LSM) were calculated for all variables.

\section{RESULTS}

\section{Light-Dark Box Test}

The results are presented in Table 1 . Treatment did not affect any of the anxiety-related variables, neither per se nor in interaction with the genetic background. The following measures varied among strains: latency to enter the dark compartment: $F 2,59=5.71, \mathrm{p}<0.01(\mathrm{~B} 6=\mathrm{NZB}<\mathrm{CBA})$; time spent in the light compartment: $F 2,59=7.47, p<0.01 \quad(\mathrm{NZB}=\mathrm{B} 6<\mathrm{CBA})$; crosses: F2,59=8.15, $\mathrm{p}<0.001(\mathrm{CBA}<\mathrm{NZB}=\mathrm{B} 6)$.

\section{Aggression Test}

Results are presented in Table 2 . In both tests strain differences were observed for all variables.

Neutral cage: attack latency: $\mathrm{F}_{2,67}=5.01 ; \mathrm{p}<0.01(\mathrm{CBA}=$ $\mathrm{NZB}<\mathrm{B} 6)$; attacks: $\mathrm{F}_{2,67}=6.60, \mathrm{p}<0.01(\mathrm{~B} 6<\mathrm{NZB}=\mathrm{CBA})$; tail rattles: $\quad \mathrm{F}_{2,67}=4.00, \mathrm{p}<0.05 \quad(\mathrm{~B} 6=\mathrm{CBA}, \quad \mathrm{CBA}=\mathrm{NZB}, \mathrm{B} 6<$ NZB).

Resident intruder paradigm: attack latency: $\mathrm{F}_{2,67}=19.46$; $\mathrm{p}<0.001(\mathrm{CBA}<\mathrm{NZB}<\mathrm{B} 6)$; attacks: $\mathrm{F}_{2,67}=9.97 \mathrm{p}<0.001$ (B6= $\mathrm{NZB}<\mathrm{CBA}$ ); tail rattles: $\mathrm{F}_{2,67}=8.17, \mathrm{p}<0.001 \quad(\mathrm{~B} 6=\mathrm{NZB}<$ CBA). Neither a treatment effect per se nor an interaction between treatment and strain were detected.

\section{Radial-Maze Test}

The results of the radial maze test are presented in Fig. (1). Treatment did not affect radial maze learning, neither alone or in interaction with days or strain. By contrast, strain differences as well as day effects were found for both the number of errors and the new entries (errors: STRAIN: $\mathrm{F}_{2,58}=3.22, \mathrm{p}<0.05, \mathrm{~B} 6>\mathrm{CBA}, \mathrm{B} 6=\mathrm{NZB}, \mathrm{CBA}=\mathrm{NZB}$; DAY: $\mathrm{F}_{2,116}=12.49 \mathrm{p}<0.001$; new entries: STRAIN: $\mathrm{F}_{2,64}=11.94$, $\left.\mathrm{p}<0.001, \mathrm{~B} 6<\mathrm{NZB}=\mathrm{CBA} ; \mathrm{DAY}: \mathrm{F}_{2,128}=9.31, \mathrm{p}<0.001\right)$. No interactions between day and strain were detected. More detailed analyses showed that on day 4 and 5, CBA made less errors than B6 (both days $\mathrm{p}<0.01$ ). As for new entries, none of the groups performed above chance level on any given day. 
Table 1. Results of the Light-Dark Box Test

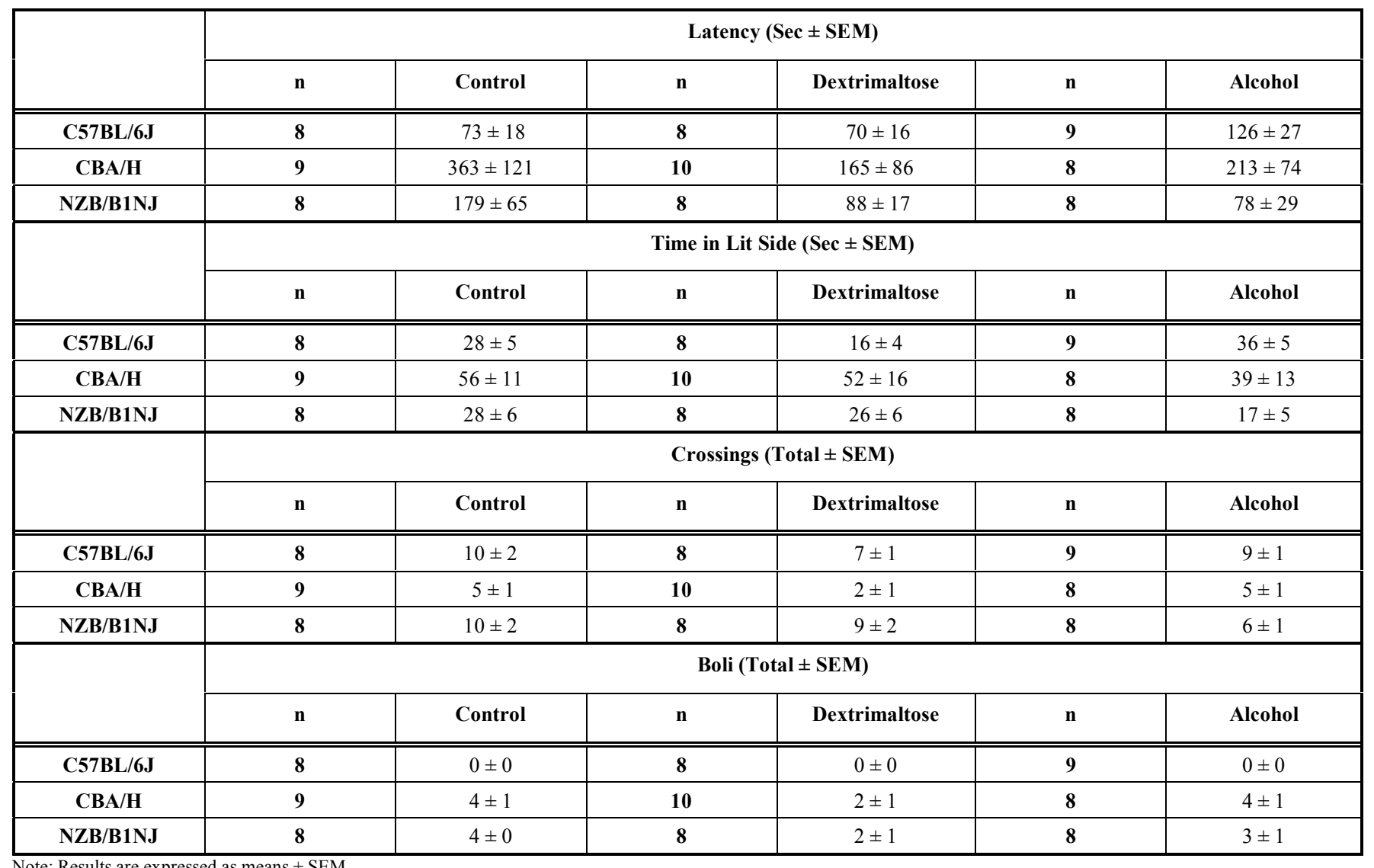

Note: Results are expressed as means \pm SEM.

Table 2. Results of the Intermale Aggression Tests

\begin{tabular}{|c|c|c|c|c|c|c|c|}
\hline & \multicolumn{6}{|c|}{ Attack Latency (Sec \pm SEM) } & \multirow{10}{*}{ 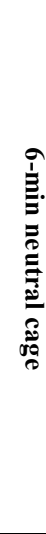 } \\
\hline & $\mathbf{n}$ & Control & n & Dextrimaltose & $\mathbf{n}$ & Alcohol & \\
\hline $\mathrm{C} 57 \mathrm{BL} / 6 \mathrm{~J}$ & 8 & $360 \pm 0$ & 8 & $360 \pm 0$ & 9 & $360 \pm 0$ & \\
\hline $\mathrm{CBA} / \mathrm{H}$ & 9 & $316 \pm 26$ & 10 & $304 \pm 35$ & 8 & $252 \pm 42$ & \\
\hline \multirow[t]{3}{*}{ NZB/B1NJ } & 8 & $334 \pm 17$ & 8 & $287 \pm 39$ & 8 & $312 \pm 38$ & \\
\hline & \multicolumn{6}{|c|}{$\%$ Attacking Males } & \\
\hline & $\mathbf{n}$ & Control & $\mathbf{n}$ & Dextrimaltose & $\mathbf{n}$ & Alcohol & \\
\hline $\mathrm{C} 57 \mathrm{BL} / 6 \mathrm{~J}$ & 8 & 0 & 8 & 0 & 9 & 0 & \\
\hline $\mathrm{CBA} / \mathrm{H}$ & 9 & 38 & 10 & 63 & 8 & 63 & \\
\hline \multirow[t]{3}{*}{ NZB/B1NJ } & 8 & 25 & 8 & 50 & 8 & 37 & \\
\hline & \multicolumn{6}{|c|}{ Attack Latency $(\mathrm{Sec} \pm \mathrm{SEM})$} & \multirow{10}{*}{ 章. } \\
\hline & $\mathbf{n}$ & Control & $\mathbf{n}$ & Dextrimaltose & $\mathbf{n}$ & Alcohol & \\
\hline $\mathrm{C} 57 \mathrm{BL} / 6 \mathrm{~J}$ & 8 & $349 \pm 11$ & 8 & $360 \pm 0$ & 9 & $360 \pm 0$ & \\
\hline $\mathrm{CBA} / \mathrm{H}$ & 9 & $319 \pm 20$ & 10 & $254 \pm 36$ & 8 & $207 \pm 39$ & \\
\hline \multirow[t]{3}{*}{$\mathrm{NZB/B} 1 \mathrm{NJ}$} & 8 & $344 \pm 16$ & 8 & $289 \pm 30$ & 8 & $333 \pm 24$ & \\
\hline & \multicolumn{6}{|c|}{$\%$ Attacking Males } & \\
\hline & $\mathbf{n}$ & Control & $\mathbf{n}$ & Dextrimaltose & $\mathbf{n}$ & Alcohol & \\
\hline $\mathrm{C} 57 \mathrm{BL} / 6 \mathrm{~J}$ & 8 & 0 & 8 & 0 & 9 & 0 & \\
\hline $\mathrm{CBA} / \mathrm{H}$ & 9 & 44 & 10 & 70 & 8 & 88 & \\
\hline NZB/B1NJ & 8 & 13 & 8 & 50 & 8 & 25 & \\
\hline
\end{tabular}




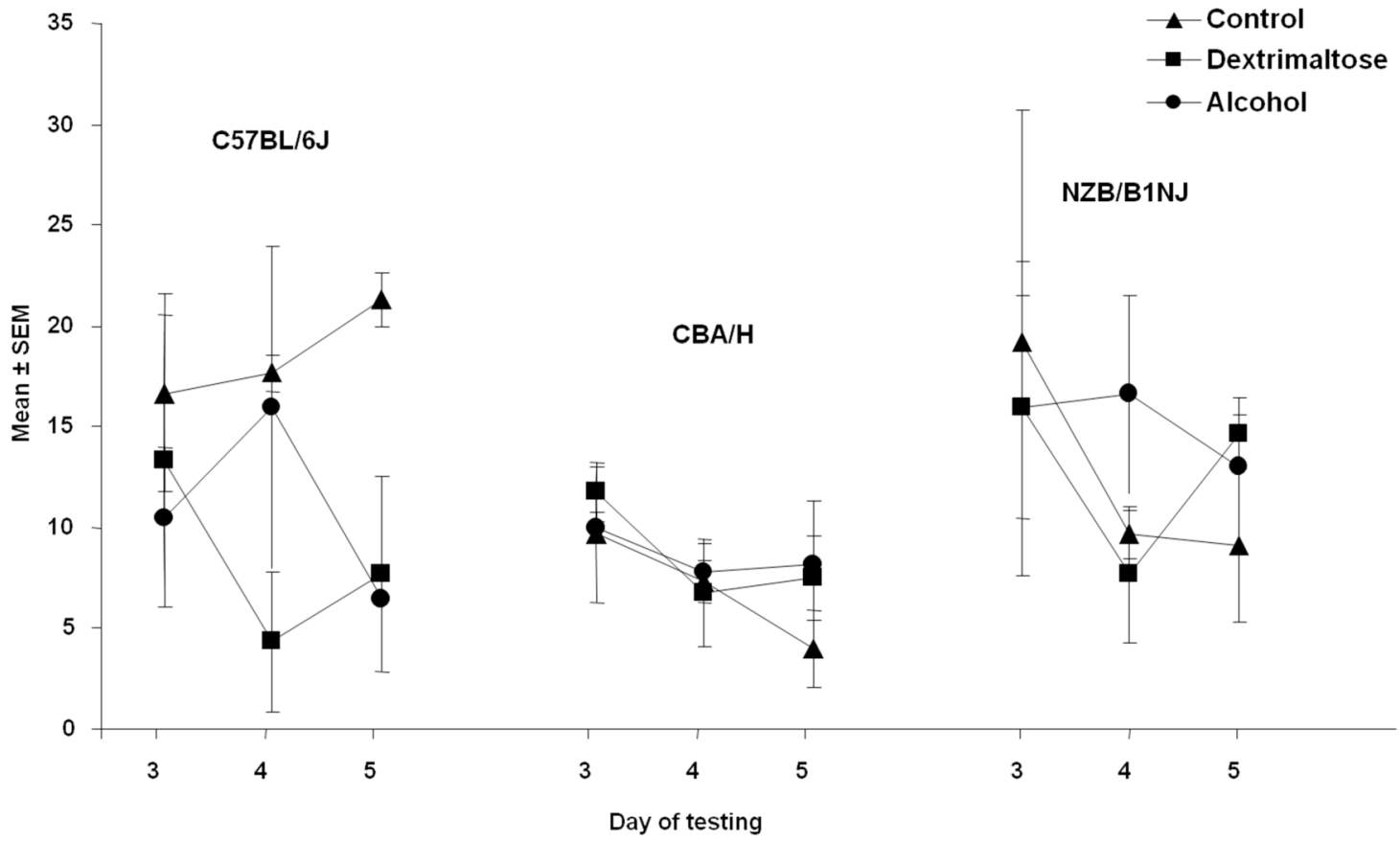

Fig. (1). Radial maze learning in male mice from three different inbred strains after 6 months of chronic alcohol consumption. Data presented are mean numbers of errors \pm SEM.

\section{Hippocampal Morphometry}

The sizes of the IIPMF terminal fields are shown in Fig. (2) while the other hippocampal variables are displayed in Table 3. Strain differences were observed for all variables: IIPMF: $\mathrm{F}_{2,51}=45.34, \mathrm{p}<0.001, \mathrm{~B} 6>\mathrm{CBA}>\mathrm{NZB}$; suprapyramidal MF: $\quad F_{2,51}=12.67 ; \quad \mathrm{p}<0.001, \quad \mathrm{~B} 6<\mathrm{NZB}=\mathrm{CBA} ; \quad \mathrm{CA} 4$ : $\mathrm{F}_{2,51}=9.94, \mathrm{p}<0.001, \mathrm{CBA}=\mathrm{B} 6<\mathrm{NZB}$. No treatment effects were detected.

\section{DISCUSSION}

The goal of this study was to investigate the genetic susceptibility to chronic exposure of alcohol on specific neurobehavioral variables in three inbred strains of mice. Unexpectedly, chronic alcohol administration appeared not to influence the sizes of the IIPMF terminal fields nor did it appear to affect radial maze learning, aggression, and anxietylike behavior. Interactions with the genetic background were not observed either.

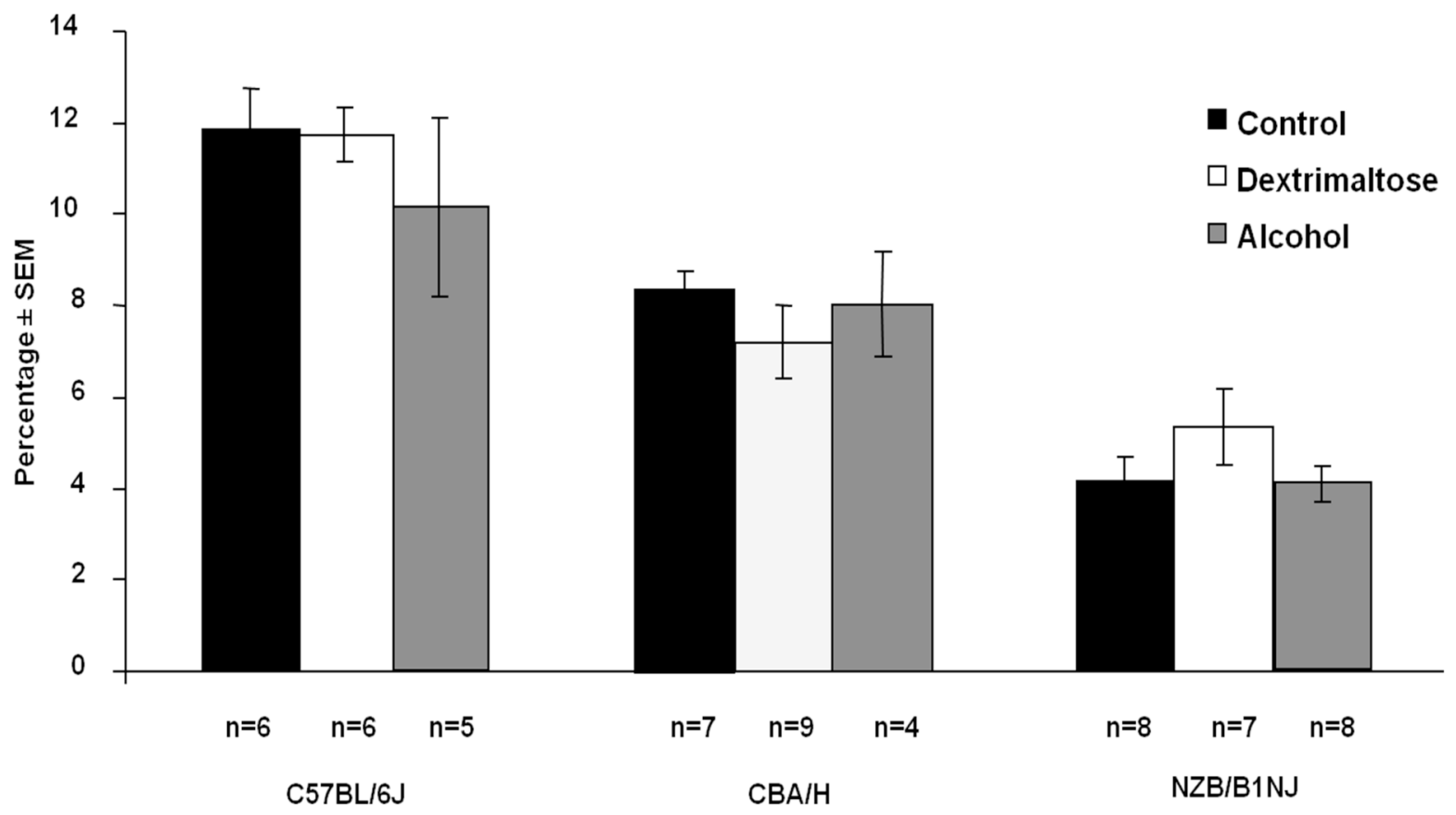

Fig. (2). Sizes of the intra- and infrapyramidal mossy fiber terminal fields in male mice from three different inbred strains after 6 months of chronic alcohol consumption. Results are expressed as mean percentage of total mossy fibers $\pm \mathrm{SEM}$. 
Table 3. Sizes of the Suprapyramidal and CA4 Mossy Fiber Terminal Fields

\begin{tabular}{|c|c|c|c|c|c|c|}
\hline & \multicolumn{6}{|c|}{ Suprapyramidal Layer (\% of Total Mossy Fibers Surface) } \\
\hline & $\mathbf{n}$ & Control & $\mathbf{n}$ & Dextrimaltose & $\mathbf{n}$ & Alcohol \\
\hline C57BL/6J & 6 & $37 \pm 1$ & 6 & $39 \pm 1$ & 5 & $39 \pm 1$ \\
\hline CBA/H & 7 & $45 \pm 1$ & 9 & $45 \pm 1$ & 4 & $42 \pm 1$ \\
\hline \multirow[t]{3}{*}{ NZB/B1NJ } & 8 & $41 \pm 2$ & 7 & $42 \pm 1$ & 8 & $43 \pm 2$ \\
\hline & \multicolumn{6}{|c|}{ CA4 (\% of Total Mossy Fibers Surface) } \\
\hline & $\mathbf{n}$ & Control & $\mathbf{n}$ & Dextrimaltose & $\mathbf{n}$ & Alcohol \\
\hline $\mathrm{C} 57 \mathrm{BL} / 6 \mathrm{~J}$ & 6 & $51 \pm 1$ & 6 & $50 \pm 1$ & 5 & $50 \pm 1$ \\
\hline $\mathrm{CBA} / \mathrm{H}$ & 7 & $47 \pm 1$ & 9 & $48 \pm 2$ & 4 & $50 \pm 1$ \\
\hline NZB/B1NJ & 8 & $55 \pm 2$ & 7 & $53 \pm 1$ & 8 & $53 \pm 2$ \\
\hline
\end{tabular}

The absence of effects of chronic alcohol intake is unlikely to be explained by the design of the experiment. The duration of the alcohol exposure (6 months) as well as the concentration of the alcohol solution used here have been demonstrated to affect behavior as well as brain anatomy in several independent studies [16, 20,43-48], although some reports suggest that a longer exposure is necessary to have an effect on specific anatomical features of the hippocampus [6]. In addition, it is improbable that the 5-week withdrawal period resulted in recovery of initially present alcohol effects, as previous studies have shown that the loss of pyramidal and granule cells is long-lasting $[17,20]$. In fact, withdrawal may worsen the effects of chronic alcohol exposure rather than lead to recovery [5].

One obvious possible explanation for the absence of effects is that the blood ethanol levels in our animals may have been too low to have an effect. However, this is unlikely as mice from our alcohol group were exposed to relatively high alcohol concentrations during a prolonged period of time as their only source of liquid and were drinking similar fluid amounts as both control groups. An alternative explanation for the surprising absence of ethanol effects might be a difference in the species used. Differences between rat and mouse models have been reported before [44, 49] and most studies that reported negative effects of protracted alcohol exposure, such as general learning disabilities and neuronal loss $[3,10,14,45-48]$, were conducted in rats. Mice have been used only rarely, which makes it difficult to generalize and compare. For instance, rats metabolize ethanol almost twice as slow as mice [50], although this does not necessarily lead to higher blood ethanol concentrations [51]. In addition, Béracochéa and collaborators showed that the memory deficits observed in mice after chronic alcohol exposure, are rather specific [52-55]. As for possible hippocampal damage in mice, Béracochéa himself later stated that "no major changes were observed in the hippocampus" of chronic alcohol consumption exposed mice and that chronic alcoholinduced amnesia "is not due to a dysfunction of the neural networks underlying memory storage processes" [56]. In addition, it is perhaps worth noting that in a previous study [57], we did not find the effects of prenatal exposure to ethanol reported in rats [58]. Hence, together with our current findings, this suggests that, in order to mimic the effects of chronic alcohol exposure in humans, mouse models are either less suitable than rat models (where both neuronal and behavioral effects are observed) or should be approached at a different level [16,59].

The lack of treatment effects might also be related to the age of testing. At the time they were sacrificed, the animals were 10-11 months of age. Bearing in mind that aging effects are generally observed from 9 months on, possible negative influences of alcohol consumption may have been buffered, or even masked, by aging effects. Indeed, the size of the mossy fiber terminal fields has been shown to diminish over age [60], so a floor effect may have masked any effect of the alcohol treatment. The radial maze data support this explanation, as the absence of treatment effects here is most probably due to a floor effect. Even control animals showed only weak learning: the numbers of errors and new entries changed significantly over training and significant strain differences were observed, but in the end no single group performed significantly better than chance. Comparing our results with previously obtained data from younger animals of these strains, it is evident that learning performances in our controls were drastically lower than in untreated 3months-old animals $[35,61]$.

\section{CONCLUSIONS}

Summarizing, despite a constant exposure to a $15 \%$ alcohol-containing solution as their only beverage for 6 months, male mice from the $\mathrm{C} 57 \mathrm{BL} / 6 \mathrm{~J}, \mathrm{CBA} / \mathrm{H}$ and NZB inbred strains did not differ from pair-fed and control groups with respect to the sizes of the hippocampal intra- and infrapyramidal mossy fiber (IIPMF) terminal fields, radial maze learning, aggression, and anxiety-like behavior. Accordingly, our data indicate that, under these experimental conditions and within the limits discussed above, chronic alcohol exposure has no effect on the observed neurobehavioral variables.

\section{ACKNOWLEDGEMENTS}

FS was supported by a Talent Stipend (S88-204) from the Netherlands Organization for Scientific Research (NWO). This research was supported by a grant (number 95/09) from the Institut de Recherche sur les Boissons (IREB, Paris, France) to WEC. 


\section{REFERENCES}

[1] Neiman J, Alcohol as a risk factor for brain damage: neurologic aspects. Alcohol Clin Exp Res 1998; 22: 346S-51S.

[2] Agartz I, Momenan R, Rawlings RR, Kerich MJ, Hommer DW, Hippocampal volume in patients with alcohol dependence. Arch Gen Psychiatry 1999; 56: 356-63.

[3] Arendt T, Impairment in memory function and neurodegenerative changes in the cholinergic basal forebrain system induced by chronic intake of ethanol. J Neural Transm Suppl 1994; 44: 173-87.

[4] Paula-Barbosa MM, Brandao F, Madeira MD, Cadete-Leite A, Structural changes in the hippocampal formation after long-term alcohol consumption and withdrawal in the rat. Addiction 1993; 88: 237-47.

[5] Cadete-Leite A, Tavares MA, Paula-Barbosa MM, Alcohol withdrawal does not impede hippocampal granule cell progressive loss in chronic alcohol-fed rats. Neurosci Lett 1988; 86: 45-50.

[6] Cadete-Leite A, Tavares MA, Pacheco MM, Volk B, PaulaBarbosa MM, Hippocampal mossy fiber-CA3 synapses after chronic alcohol consumption and withdrawal. Alcohol 1989; 6: 303-10.

[7] Lukoyanov NV, Brandao F, Cadete-Leite A, Madeira MD, PaulaBarbosa MM, Synaptic reorganization in the hippocampal formation of alcohol-fed rats may compensate for functional deficits related to neuronal loss. Alcohol 2000; 20: 139-48.

[8] Tapia-Arancibia L, Rage F, Givalois L, Dingeon P, Arancibia S, Beaugé F. Effects of alcohol on brain-derived neurotrophic factor mRNA expression in discrete regions of the rat hippocampus and hypothalamus. Journal of Neuroscience Research 2001; 63: 200-08.

[9] MacLennan AJ, Lee N, Walker DW, Chronic ethanol administration decreases brain-derived neurotrophic factor gene expression in the rat hippocampus. Neurosci Lett 1995; 197: 105-08.

[10] Melis F, Stancampiano R, Imperato A, Carta G, Fadda F, Chronic ethanol consumption in rats: correlation between memory performance and hippocampal acetylcholine release in vivo. Neurosci 1996; 74: 155-59.

[11] Pulvirenti L, Diana M, Drug dependence as a disorder of neural plasticity: Focus on dopamine and glutamate. Rev Neurosci 2001; 12: 141-58.

[12] Fadda F, Cocco S, Stancampiano R, Rossetti ZL, Long-term voluntary ethanol consumption affects neither spatial nor passive avoidance learning, nor hippocampal acetylcholine release in alcoholpreferring rats. Behav Brain Res 1999; 103: 71-76.

[13] Gibson MA, Butters NS, Reynolds JN, Brien JF, Effects of chronic prenatal ethanol exposure on locomotor activity, and hippocampal weight, neurons, and nitric oxide synthase activity of the young postnatal guinea pig. Neurotoxicol Teratol 2000; 22: 183-92.

[14] Walker DW, Hunter BE, Abraham WC, Neuroanatomical and functional deficits subsequent to chronic ethanol administration in animals. Alcohol Clin Exp Res 1981; 5: 267-82.

[15] Cadete-Leite A, Brandao F, Tajrine D, Antunes S, Ribeiro da Silva A, Andrade JP. Intracerebral grafts promote recovery of the cholinergic innervation of the hippocampal formation in rats withdrawn from chronic alcohol intake. An immunocytochemical study. Neurosci 1997; 79: 383-97.

[16] Lescaudron L, Jaffard R, Verna A, Modifications in number and morphology of dendritic spines resulting from chronic ethanol consumption and withdrawal: a Golgi study in the mouse anterior and posterior hippocampus. Exp Neurol 1989; 106: 156-63.

[17] Cadete-Leite A, Tavares MA, Uylings HB, Paula-Barbosa M, Granule cell loss and dendritic regrowth in the hippocampal dentate gyrus of the rat after chronic alcohol consumption. Brain Res 1988; 473: 1-14.

[18] Tuck RR, Jackson M, Social, neurological and cognitive disorders in alcoholics. Med J Aust 1991; 155: 225-29.

[19] Radel M, Goldman D, Pharmacogenetics of alcohol response and alcoholism: the interplay of genes and environmental factors in thresholds for alcoholism. Drug Metab Dispos 2001; 29: 489-94.

[20] Riley JN, Walker DW, Morphological alterations in hippocampus after long-term alcohol consumption in mice. Science 1978; 201: 646-48.

[21] Gaarskjaer FB, The organization and development of the hippocampal mossy fiber system. Brain Res 1986; 396: 335-57.

[22] Lewin GR, Barde YA, Physiology of the neurotrophins. Annual Review of Neuroscience 1996; 19: 289-317.

[23] Lindsay RM, Wiegand SJ, Altar CA, DiStefano PS, Neurotrophic factors: from molecule to man. Trends Neurosci 1994; 17: 182-90.
[24] Crusio WE, Schwegler H, Lipp H-P, Radial-maze performance and structural variation of the hippocampus in mice: a correlation with mossy fibre distribution. Brain Res 1987; 425: 182-85.

[25] Crusio WE, Schwegler H, Brust I, Covariations between hippocampal mossy fibres and working and reference memory in spatial and non-spatial radial maze tasks in mice. Eur J Neurosci 1993; 5: 1413-20.

[26] Guillot P-V, Roubertoux PL, Crusio WE, Hippocampal mossy fiber distributions and intermale aggression in seven inbred mouse strains. Brain Res 1994; 660: 167-69.

[27] Sluyter F, Jamot L, van Oortmerssen GA, Crusio WE, Hippocampal mossy fiber distributions in mice selected for aggression. Brain Res 1994; 646: 145-48.

[28] Lipp H-P, Schwegler H, Hippocampal mossy fibers and avoidance learning, in: Lieblich I, Ed. Genetics of the Brain. Elsevier Biomedical: Amsterdam, The Netherlands, 1983; 326-58, pp.

[29] Lipp H-P, Schwegler H, Crusio WE, et al. Using geneticallydefined rodent strains for the identification of hippocampal traits relevant for two-way avoidance behavior: a non-invasive approach. Experientia 1989; 45: 845-59.

[30] Crawley J, Goodwin FK, Preliminary report of a simple animal behavior model for the anxiolytic effects of benzodiazepines. Pharmacol Biochem Behav 1980; 13: 167-70.

[31] Costall B, Kelly ME, Naylor RJ, Onaivi ES, Actions of buspirone in a putative model of anxiety in the mouse. Journal of Pharmacy and Pharmacology 1988; 40: 494-500.

[32] Costall B, Coughlan J, Horovitz ZP, Kelly ME, Naylor RJ, Tomkins DM. The effects of ACE inhibitors captopril and SQ29,852 in rodent tests of cognition. Pharmacol Biochem Behav 1989; 33: 573-79.

[33] Misslin R, Belzung C, Vogel E, Interaction of RO 15-4513 and ethanol on the behaviour of mice: antagonistic or additive effects? Psychopharmacol 1988; 94: 392-96.

[34] Guillot P-V, Chapouthier G, Intermale aggression and dark/light preference in ten inbred mouse strains. Behav Brain Res 1996; 77 : 211-13.

[35] Sluyter F, Marican CCM, Roubertoux PL, Crusio WE, Radial maze learning in two inbred mouse strains and their reciprocal congenics for the non-pseudoautosomal region of the Y chromosome. Brain Res 1999; 835: 68-73.

[36] Roubertoux PL, LeRoy I, Mortaud S, Perez-Diaz F, Tordjman S, Measuring aggression in the mouse, in: Crusio WE and Gerlai R, Eds. Handbook of Molecular-Genetic Techniques for Brain and Behavior Research. Elsevier: Amsterdam, 1999; 696-709, pp.

[37] Carlier M, Roubertoux P, Differences between CBA/H and NZB mice on intermale aggression, in: Médioni J and Vaysse G, Eds. Genetic Approaches to Behaviour. Privat: Toulouse, 1986; 47-57, pp.

[38] Schwegler H, Crusio WE, Brust I, Hippocampal mossy fibers and radial-maze learning in the mouse: a correlation with spatial working memory but not with non-spatial reference memory. Neurosci 1990; 34: 293-98.

[39] Olton DS, Feustle WA, Hippocampal function required for nonspatial working memory. Exp Brain Res 1981; 41:380-89.

[40] Schwegler H, Lipp H-P, Hereditary covariations of neuronal circuitry and behavior: correlations between the proportions of hippocampal synaptic fields in the regio inferior and two-way avoidance in mice and rats. Behav Brain Res 1983; 7: 1-38.

[41] Danscher G, Zimmer J, An improved Timm sulphide silver method for light and electron microscopic localization of heavy metals in biological tissues. Histochemistry 1978; 55: 27-40.

[42] Mineur YS, Crusio WE, Behavioral and neuroanatomical characterization of FVB/N inbred mice. Brain Res Bull 2002; 57: 41-47.

[43] Lescaudron L, Verna A, Effects of chronic ethanol consumption on pyramidal neurons of the mouse dorsal and ventral hippocampus: a quantitative histological analysis. Exp Brain Res 1985; 58: 362-67.

[44] Browman KE, Crabbe JC, Alcohol and genetics: new animal models. Mol Med Today 1999; 5: 310-18.

[45] Walker DW, Freund G, Impairment of shuttle box avoidance learning following prolonged alcohol consumption in rats. Physiol Behav 1971; 7: 773-78.

[46] Walker DW, Freund G, Impairment of timing behavior after prolonged alcohol consumption in rats. Science 1973; 182: 597-99.

[47] Walker DW, Hunter BE, Prolonged alcohol consumption in the rat: absence of retrograde amnesia for an avoidance response. Pharmacol Biochem Behav 1974; 2: 63-66. 
[48] Walker DW, Hunter BE, Short-term memory impairment following chronic alcohol consumption in rats. Neuropsychologia 1978; 16: 545-53.

[49] Foroud T, Li TK, Genetics of alcoholism: A review of recent studies in human and animal models. Am J Addict 1999; 8: 261-78.

[50] Abel EL, Behavioral teratology of alcohol, in: Abel EL, Ed. Fetal Alcohol Syndrome: Animal Studies. CRC Press: Boca Raton, FL, USA, 1982; 59-81, pp.

[51] Livy DJ, Parnell SE, West JR, Blood ethanol concentration profiles: a comparison between rats and mice. Alcohol 2003; 29: 16571.

[52] Béracochéa D, Durkin TP, Jaffard R, On the involvement of the central cholinergic system in memory deficits induced by long term ethanol consumption in mice. Pharmacol Biochem Behav 1986; 24: $519-24$.

[53] Béracochéa D, Jaffard R, Memory deficits subsequent to chronic consumption of alcohol in mice: an analysis based on spontaneous alternation behavior. Behav Brain Res 1985; 15: 15-25.

[54] Béracochéa D, Jaffard R, Effects of chronic ethanol consumption associated or not with experimental anterior thalamic lesions on spontaneous sequential alternation in mice. Neurosci Lett 1991; 134: 45-48.
[55] Béracochéa D, Micheau J, Jaffard R, Memory deficits following chronic alcohol consumption in mice: relationships with hippocampal and cortical cholinergic activities. Pharmacol Biochem Behav 1992; 42: 749-53.

[56] Béracochéa $\mathrm{D}$, Modèle animal de l'amnésie d'origine alcoolique: Une amnésie sans atteinte de la mémoire. Therapie 2000; 55: 493501.

[57] Sluyter F, Jamot L, Bertholet J-Y, Crusio WE, Prenatal exposure to alcohol does not affect radial maze learning and hippocampal mossy fiber sizes in three inbred strains of mouse. Behav Brain Func 2005; 1: 5.

[58] West JR, Pierce DR, The effect of in utero ethanol exposure on hippocampal mossy fibers: an HRP study. Dev Brain Res 1984; 15 : 275-79.

[59] Borde N, Béracochéa DJ, Effects of diazepam or chronic alcohol treatment on spatial reversal learning in mice. Pharmacol Biochem Behav 1999; 62: 719-25.

[60] Barkats M, Bertholet JY, Cohen-Salmon C, Age-related morphological changes in the hippocampus in two mouse strains. Mech Ageing Dev 1996; 87: 155-64.

[61] Crusio WE, Schwegler H, Learning spatial orientation tasks in the radial-maze and structural variation in the hippocampus in inbred mice. Behav Brain Func 2005; 1: 3. 